\title{
Modified vector controlled DFIG wind energy system based on barrier function adaptive sliding mode control
}

\author{
Tummala S. L. V. Ayyarao(i)
}

\begin{abstract}
Increased penetration of wind energy systems has serious concerns on power system stability. In spite of several advantages, doubly fed induction generator (DFIG) based wind energy systems are very sensitive to grid disturbances. DFIG system with conventional vector control is not robust to disturbances as it is based on PI controllers. The objective of this paper is to design a new vector control that is robust to external disturbances. To achieve this, inner current loop of the conventional vector control is replaced with sliding mode control. In order to avoid chattering effect and achieve finite time convergence, the control gains are selected based on positive semi-definite barrier function. The proposed barrier function adaptive sliding mode (BFASMC) is evaluated by testing it on a benchmark multi-machine power system model under various operating conditions. The simulated results show that the proposed method is robust to various disturbances.
\end{abstract}

Keywords: Doubly fed induction generator (DFIG), Wind power generation, Sliding mode control, Robust control

\section{Introduction}

Increased population, global warming, change in governments green policies, increased flow of funds, and decreased installation costs paved a path for Renewable energy systems. Wind energy is one of the prominent renewable systems and is consistently expanding throughout the world. More than $51 \mathrm{GW}$ of wind energy is installed in 2017 only [18] and this shows that wind energy is slowly capturing the energy market. DFIG is the most popular generator compared to others in wind energy systems. It consists of a wind turbine coupled to the shaft of the induction machine. The stator of the DFIG system is directly connected to the grid while the rotor is connected to the grid via a back to back converter which regulates the slip power. This greatly reduces the converter rating. Highly efficient independent active and reactive power control is another advantage of the DFIG system. Because of the above advantages, DFIG dominated the entire variable speed wind energy systems. But the performance of the DFIG system during grid perturbations is drastically affected [12].

Correspondence: ayyarao.tslv@gmrit.org; ayyarao.tummala@gmail.com Department of EEE, GMR Institute of Technology, Rajam 532127, India
In the conventional vector control, the converter connected on the rotor side commonly named as Rotor side converter (RSC) regulates the active and reactive power and Grid side converter (GSC) regulates the DC link voltage. The performance of the conventional vector controlled DFIG system highly depends on the PI controller parameters. Several PI controllers tuning techniques like particle swarm optimization, Differential evolution, Bacteria foraging are proposed in the literature [11, 16, 17]. These methods are based on linearized model of DFIG around an operating point. However, DFIG system is a highly nonlinear system and thus performance of the conventional vector controlled DFIG system is compromised for large disturbances like three-phase faults. Nonlinear controllers are proposed in the literature as an alternative to overcome the nonlinearity behavior of DFIG system $[3,6,14]$.

As wind speed is stochastic in nature $[5,8]$ variable power generation has drastic effect in multi-machine power systems and therefore robust control is the most effective way in dealing with DFIG system. Sliding mode control is one of the robust control techniques [15] and therefore has been implemented for 
controlling the DFIG system [4]. Nevertheless, first order sliding mode control introduces control chattering and the hardware realization requires highfrequency switching converters. To overcome this issue, second order sliding mode control techniques are applied for DFIG system [1, 2, 9]. Some of the concerns are the design of the controller assumes that the bound of the disturbance is known which may not be possible in practice and the control parameters may be overestimated. Perturbation estimation based sliding mode control is proposed in [10].

Barrier function based adaptive sliding mode control is introduced in [13]. To achieve finite time convergence, chattering free and improved robustness to various disturbances, the conventional vector controlled DFIG system is modified and the current control loop is implemented with BFASMC. BFASMC is introduced in the inner current loop to achieve faster convergence than outer control loop.

The major contributions of the paper are as follows:

1. This paper proposes a modified vector controlled DFIG based wind energy system. The proposed composite sliding mode control is a combination of PI control for outer loop and BFASMC for inner current loop dynamics. The inner current loops of both rotor side control and grid side control are designed based on BFASMC.

2. The proposed idea is simple to design and reduces control chattering as well.

3. Active power and terminal voltage deviations converge to zero in finite time post disturbance.

4. The controller is robust to various perturbations like three-phase faults on transmission lines, parametric variations, and variable wind speeds.

5. The proposed controller does not require the upper bounds of the disturbance.

The rest of the paper is organized as follows: Section 2 briefs the dynamic model of the DFIG system; Section 3 introduces BFASMC. The design of the proposed composite sliding mode control is detailed in Section 4. The proposed control technique is evaluated and tested on a benchmark multi-machine power system and the simulated results are analyzed in Section 5. Finally, concluding remarks are given in the last section.

\section{Dynamic model of DFIG based wind energy system}

The dynamics of the DFIG system are given by (1)-(3) [7]

$$
\frac{d \psi_{d r}}{d t}=V_{d r}-R_{r} i_{d r}+s \omega_{s} \psi_{q r}
$$

$$
\begin{aligned}
& \frac{d \psi_{q r}}{d t}=V_{q r}-R_{r} i_{q r}-s \omega_{s} \psi_{d r} \\
& \frac{d \omega}{d t}=\frac{1}{J}\left(T_{m}-T_{e}\right)
\end{aligned}
$$

where $\psi_{d r}$ is rotor d-axis flux linkage; $\psi_{q r}$ is rotor q-axis flux linkage; $V_{d r}$ is rotor d-axis voltage; $V_{q r}$ is rotor q-axis voltage; $i_{d r}$ is rotor $\mathrm{d}$-axis current; $i_{q r}$ is rotor $\mathrm{q}$-axis current; $s$ is the slip; $R_{r}$ is the rotor resistance; $\omega$ is the rotor speed; $J$ is the moment of inertia; $T_{m}$ is mechanical torque acting on the rotor; $T_{e}$ is the electromagnetic torque developed by the rotor.

The flux linkages are given by:

$$
\begin{aligned}
& \psi_{d r}=-L_{m} i_{d s}+L_{r r} i_{d r} \\
& \psi_{q r}=-L_{m} i_{q s}+L_{r r} i_{q r}
\end{aligned}
$$

where $i_{d s}$ is stator $\mathrm{d}$-axis current; $i_{q s}$ is stator q-axis current.

The electromagnetic torque developed by the rotor is given by:

$$
T_{e}=\psi_{q r} i_{d r}-\psi_{d r} i_{q r}
$$

The mechanical output of the wind turbine is given by:

$$
T_{m}=\frac{1}{2} \sigma A v_{w}^{3} c_{p}(\lambda, \beta)
$$

where $\sigma$ is the air density; $A$ is the area swept by the turbines; $v_{w}$ is the wind speed; $c_{p}$ is the Performance coefficient of the turbine; $\lambda$ is the tip speed ratio; $\beta$ is the pitch angle.

$$
c_{p}=\left(\frac{c_{1} c_{2}}{\lambda_{i}}-c_{1} c_{3} \beta-c_{1} c_{4}\right) e^{\frac{-c_{6}}{\lambda}}+c_{6} \lambda
$$

$c_{1}, c_{2}, c_{3}, c_{4}, c_{5}, c_{6}$ are constants and $\lambda_{i}$ is a function of $\lambda, \beta$.

The wind turbine operates with maximum power point tracking (Fig. 1).

\section{An introduction to barrier function adaptive sliding mode control}

Let us consider a system whose dynamics are given by:

$$
\dot{x}=u+d
$$

where $x \in \Re$ is the state of the system, $u \in \Re$ is the control input to the plant, $d$ is the unknown bounded disturbance acting on the system i.e., $|d| \leq d_{m}$ where $d_{m}$ is a finite positive value. Let us assume that the bounds of the disturbance acting on the system are unknown.

A First order sliding mode control (FOSMC) input required to stabilize the system is given by: 


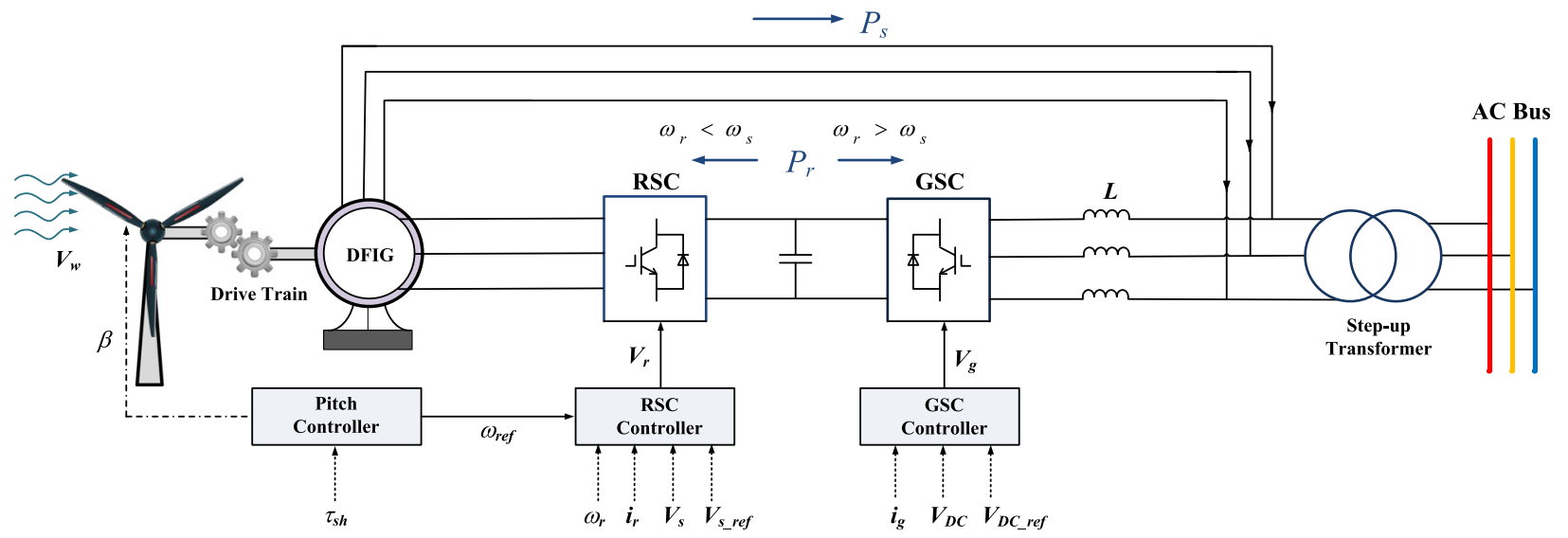

Fig. 1 DFIG based wind energy system connected to the grid

$$
u=-\mathrm{K} \operatorname{sign}(x)
$$

There are two major issues with the first order sliding mode control. The first one is a selection of optimum control gain and the second one is control chattering. For optimum control parameter selection, adaptive sliding mode control techniques are proposed in the literature. In order to minimize the control chattering, higher order sliding mode control techniques are introduced. The above two issues can be tackled using the recently proposed Barrier function based adaptive sliding mode control. The control input in (10) is modified as:

$$
u=-\hat{\mathrm{K}}(x) \operatorname{sign}(x)
$$

Now the control parameter is a function of system state and this control parameter is updated at every instant based on the positive semi-definite barrier function given by (12)

$$
\hat{K}(x)=\frac{|x|}{\Gamma-|x|}
$$

where, $\Gamma>0$ is a control parameter.

Therefore when $x \rightarrow 0, \hat{K} \rightarrow 0$. If the state $x$ is in the neighborhood of origin i.e., $\frac{|x|}{\Gamma}$ is very much less than one, then $\hat{K} \simeq \frac{|x|}{\Gamma}$. This clearly shows that the state $\mathrm{x}$ converges to zero with the BFASMC. For more details with stability proof refer [13].

\section{Control of DFIG wind energy system}

DFIG based wind energy system is a nonlinear stochastic system and is subjected to many disturbances like faults on the transmission line, parameter perturbations, and variable wind speeds. However, the conventional vector controlled DFIG system is not robust. In order to improve the robustness of conventional vector control, sliding mode control is introduced in the current control loop and accordingly, the control objectives are chosen as:

$$
\begin{aligned}
& \underset{t \rightarrow t_{F}}{L t}\left(i_{d r}-i_{d r \_r e f}\right) \rightarrow 0 \\
& \underset{t \rightarrow t_{F}}{L t}\left(i_{q r}-i_{q r \_r e f}\right) \rightarrow 0 \\
& \underset{t \rightarrow t_{F}}{L t}\left(i_{d g}-i_{d g \_r e f}\right) \rightarrow 0 \\
& \underset{t \rightarrow t_{F}}{L t}\left(i_{q g}-i_{q g \_r e f}\right) \rightarrow 0
\end{aligned}
$$

where $t_{F}$ is a finite time value and $i_{d r_{-} r e f}$ and $i_{q r_{-} r e f}$ are the reference $\mathrm{d}$-axis and q-axis currents.

In the vector controlled DFIG system with stator flux orientation, $\psi_{q s}=0$ and $\psi_{d s}=\psi_{s}$. Modifying the dynamics given in (1-2) in terms of rotor currents:

$$
\begin{aligned}
& \frac{d i_{q r}}{d t}=\frac{1}{\sigma L_{r}}\left(V_{q r}-R_{r} i_{q r}-s \omega_{s} \psi_{d r}\right) \\
& \frac{d i_{d r}}{d t}=\frac{1}{\sigma L_{r}}\left(V_{d r}-R_{r} i_{d r}+s \omega_{s} \psi_{q r}\right)
\end{aligned}
$$

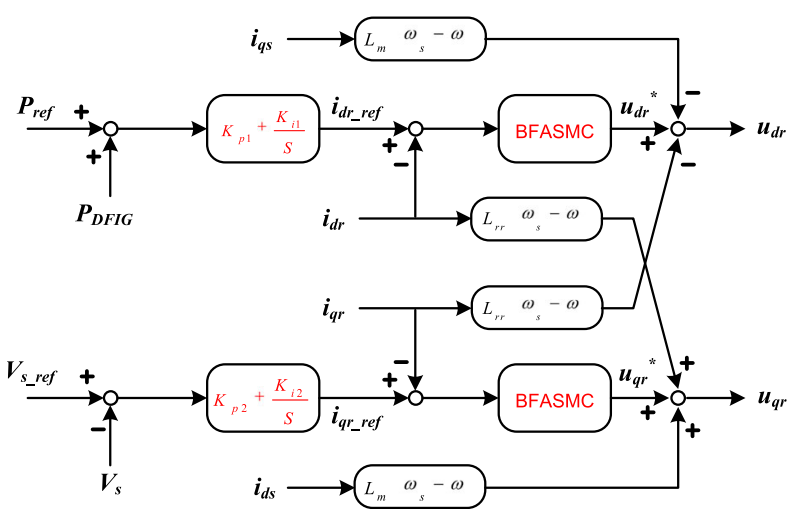

Fig. 2 Modified rotor side controller 


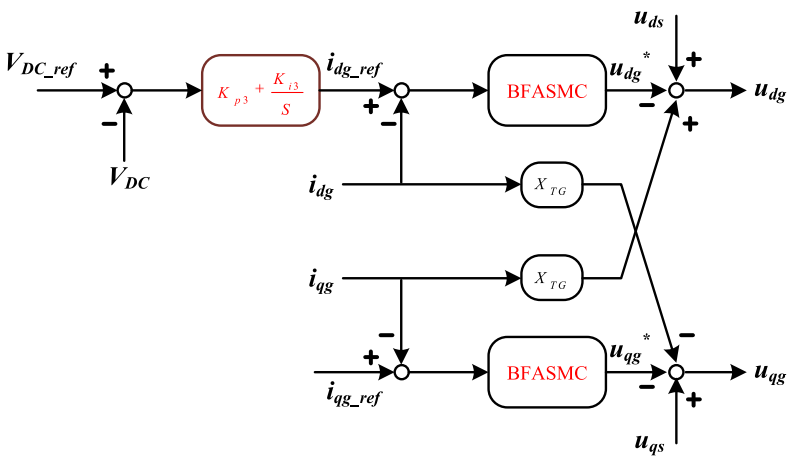

Fig. 3 Modified grid side controller

The reference rotor current $i_{d r_{-} \text {ref }}$ is generated using PI controller by comparing reference and actual active powers while the reference current $i_{q r_{-} \text {ref }}$ is generated using another PI controller using terminal voltage error. Now these currents are compared with the actual currents and current errors are generated as given (19) \& (20).

$$
\begin{aligned}
& e_{d}=i_{d r}-i_{d r \_r e f} \\
& e_{q}=i_{q r}-i_{q r \_r e f}
\end{aligned}
$$

Because of the features like chattering free, finite time convergence and simplicity in design, current controllers are designed with BFASMC.

For the design of control input in $\mathrm{d}$-axis loop, the sliding surface is selected as:

$$
\rho_{d}=e_{d}
$$

Taking the derivative of (21) and from (17), the error dynamics of $\rho_{d}$ are given as:

$$
\dot{\rho}_{d}=\frac{1}{\sigma L_{r}}\left(V_{d r}-R_{r} i_{d r}+s \omega_{s} \psi_{q r}\right)-\dot{i}_{d r \_r e f}+\phi_{d}
$$

where $\phi_{d}$ represents unmodelled dynamics and parametric variations.

Now modifying the error dynamics in (22) as:

$$
\dot{\rho}_{d}=u_{d}+\phi_{d}
$$

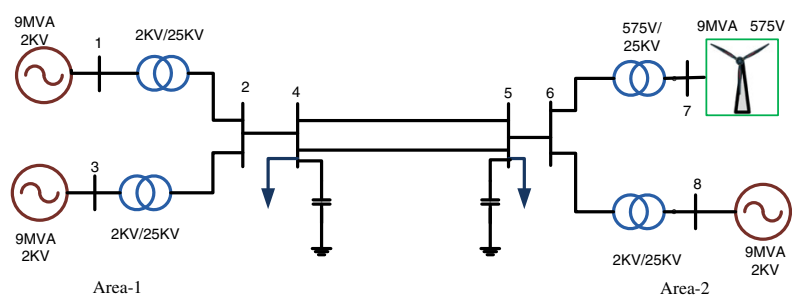

Fig. 4 Benchmark multi-machine power system

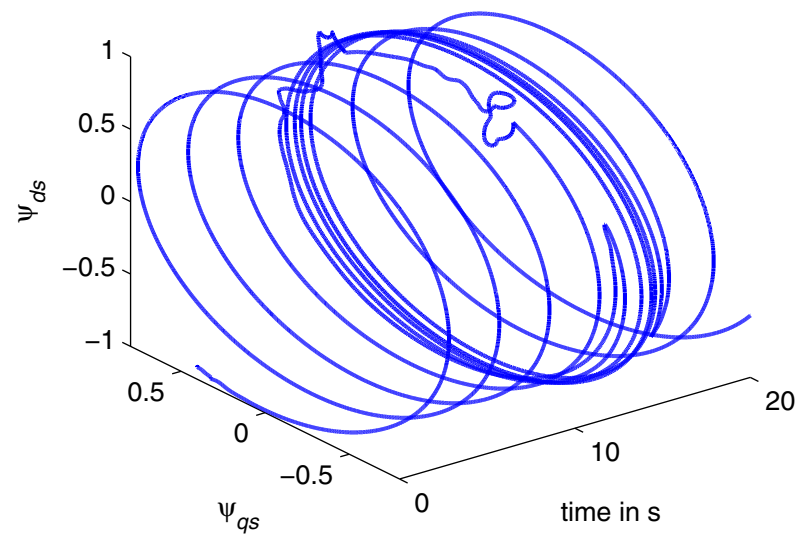

Fig. 5 3-D plot of flux linkages w.r.t time for a three-phase fault at bus 4

where

$$
u_{d}=\frac{1}{\sigma L_{r}}\left(V_{d r}-R_{r} i_{d r}+s \omega_{s} \psi_{q r}\right)
$$

and $\phi_{d}$ is the cumulative disturbance.

From (11), the control input required to stabilize the error in fixed time is given by (25)

$$
u_{d}=-\hat{K}_{d r}\left|\rho_{d}\right| \operatorname{sign}\left(\rho_{d}\right)
$$
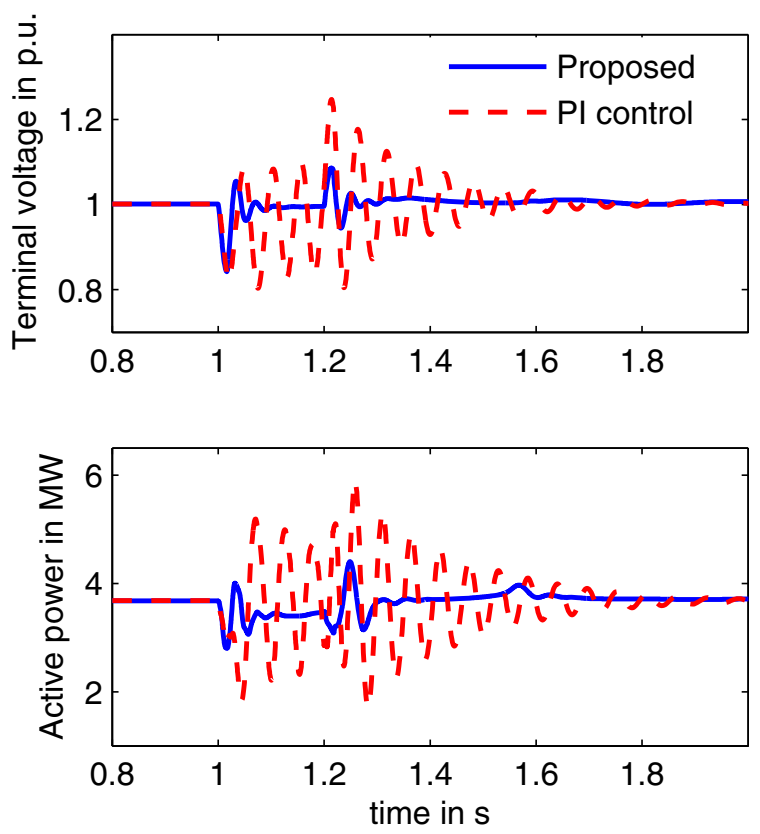

Fig. 6 Terminal voltage and active power deviations for a three-phase fault at bus 4 


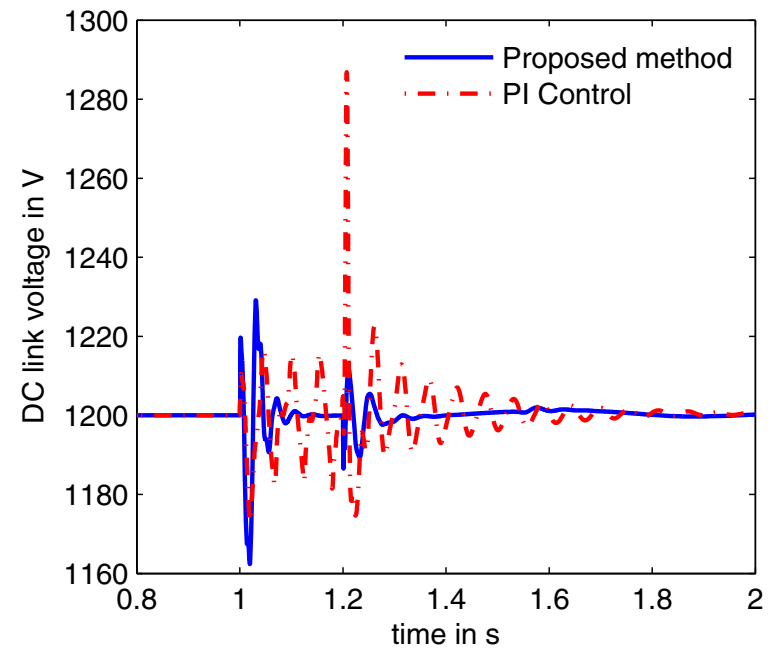

Fig. 7 DC voltage for a three-phase fault at bus 4

where

$$
\hat{K}_{d r}=\frac{\left|\rho_{d}\right|}{\Gamma_{d}-\rho_{d}}
$$

From (24),

$$
V_{d r}=\sigma L_{r} u_{d}+R_{r} i_{d r}-\omega_{s l} \psi_{q r}
$$

For the design of control input in q-axis loop, the sliding surface is chosen as:

$$
\rho_{q}=e_{q}
$$

Taking the derivative of (28) and from (18),

$$
\dot{\rho}_{q}=\frac{1}{\sigma L_{r}}\left(V_{q r}-R_{r} i_{q r}-\omega_{s l} \psi_{d r}\right)-\dot{i}_{q r-r e f}+\phi_{q}
$$
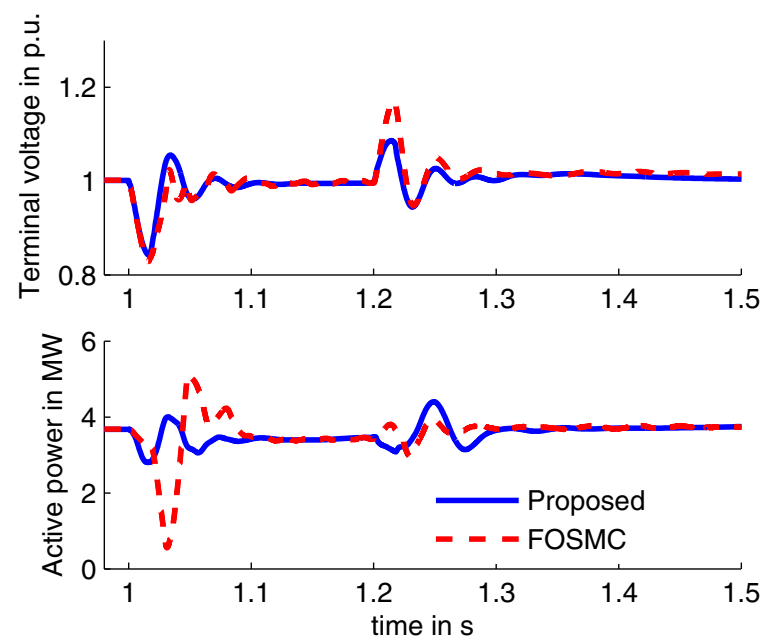

Fig. 8 Comparison of the proposed method with FOSMC

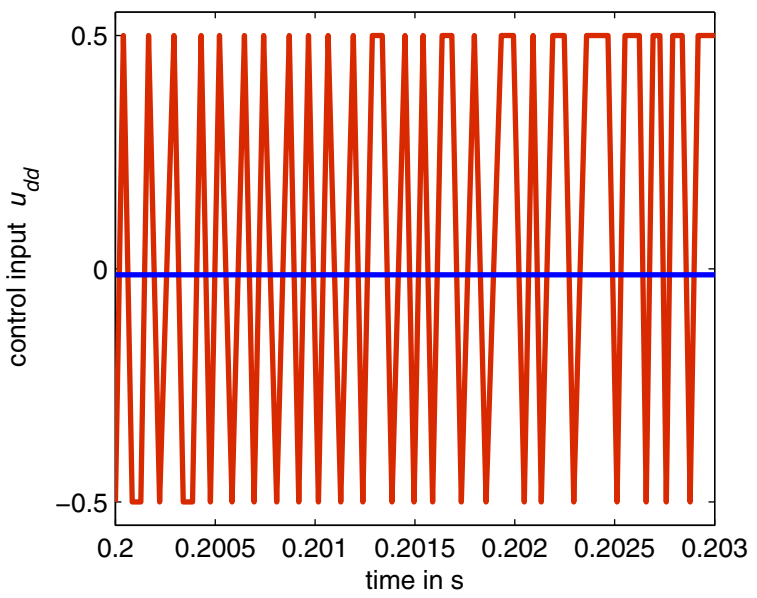

Fig. 9 Control chattering with FOSMC. Red color line indicates FOSMC and the blue one indicates the proposed method

where $\phi_{q}$ represents unmodelled dynamics and parametric variations.

Let

$$
u_{q}=\frac{1}{\sigma L_{r}}\left(V_{q r}-R_{r} i_{q r}-\omega_{s l} \psi_{d r}\right)
$$

Modifying error dynamics in (30) as:

$$
\dot{\rho}_{q}=u_{q}+\phi_{q}
$$

From (31), the control input required to stabilize the error in fixed time is:

$$
u_{q}=-\hat{K}_{q r}\left|\rho_{q}\right| \operatorname{sign}\left(\rho_{q}\right)
$$

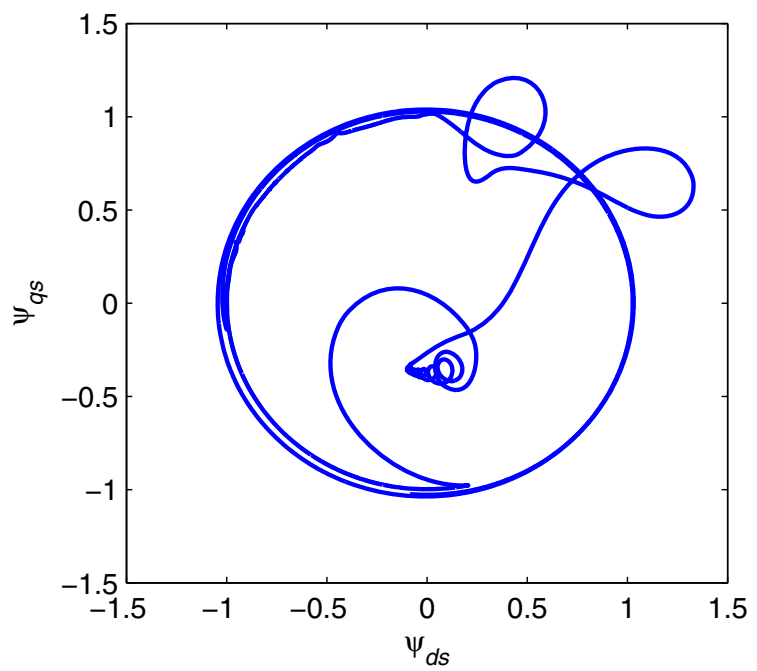

Fig. 10 Stator flux linkages 

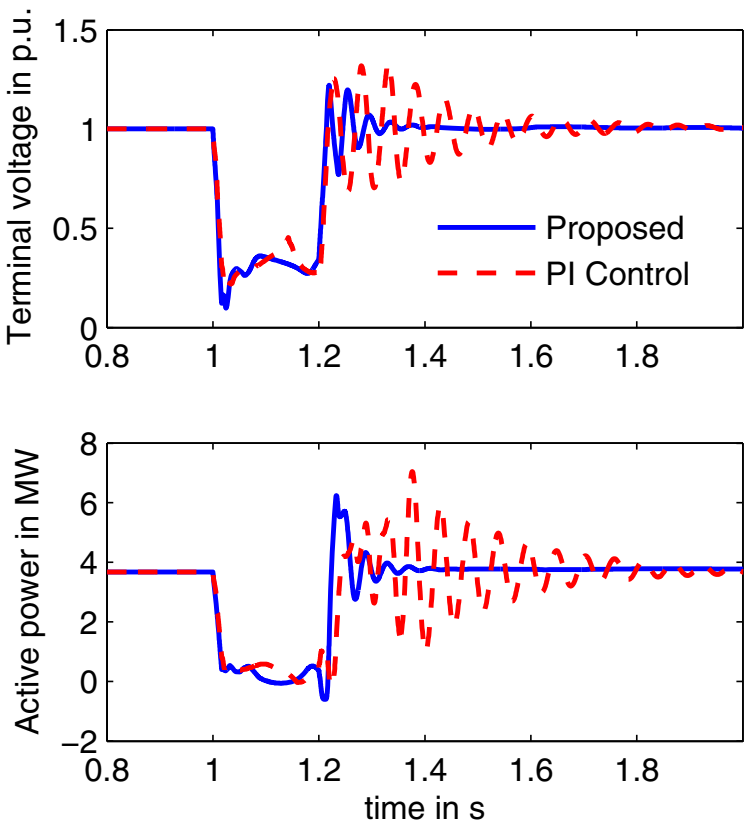

Fig. 11 Response of DFIG for a fault at bus 5

where

$$
\hat{K}_{q r}=\frac{\left|\rho_{q}\right|}{\Gamma_{q}-\rho_{q}}
$$

From (32),

$$
V_{q r}=\sigma L_{r} u_{q}+R_{r} i_{q r}+\omega_{s l} \psi_{d r}
$$

The proposed idea of rotor side converter control can be viewed from Fig. 2 .

A similar procedure is followed for the design of grid side control as shown in Fig. 3. DC link voltage

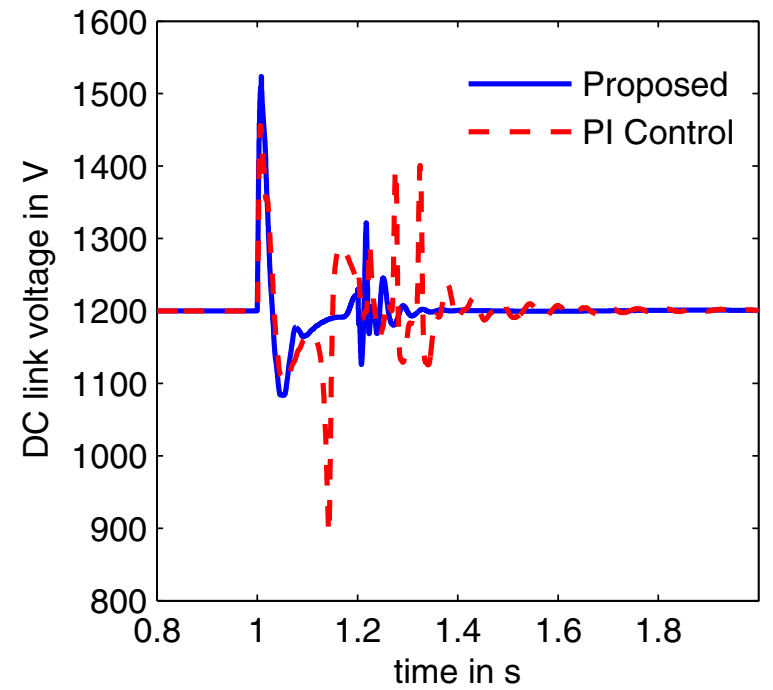

Fig. 12 DC link voltage for a three-phase fault at bus 5
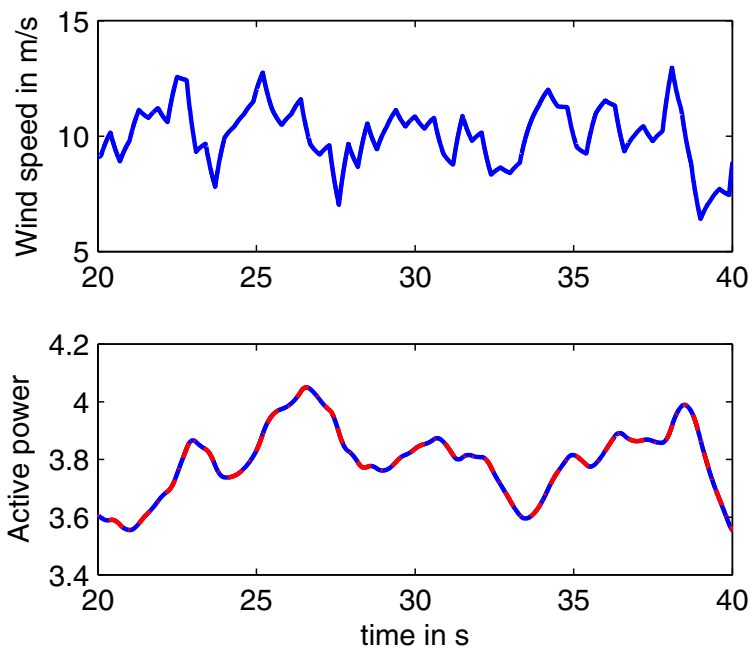

Fig. 13 Response of DFIG system for variable wind speed

is compared with the reference voltage and voltage error is given to PI controller which generates the reference current $i_{d g \_r e f}$ BFASMC is used in the design of the current control.

Remarks: The control parameters $\Gamma_{q} \Gamma_{d}$ are selected based on the maximum possible current errors $e_{q}$ and $e_{d}$ respectively.

\section{Results and discussion}

The proposed composite sliding mode control is evaluated by testing in a simulated environment MATLAB/ Simulink. In order to observe the robustness of the proposed control idea, it is tested for various test conditions for a benchmark multi-machine power system model. This benchmark system is a modified two

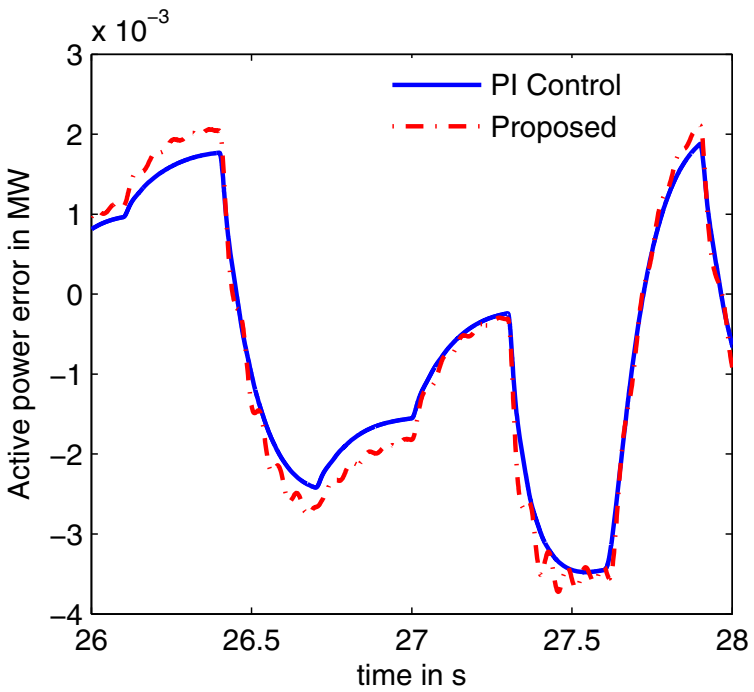

Fig. 14 Active power error for variable wind speed 
area Kundur's model [16, 17], (Feng [3]) with one of the synchronous generator replaced with DFIG based wind energy system as shown in Fig. 4. The detailed report of the benchmark system is given in [19].

\subsection{A three-phase fault on bus 4}

As the power system is a large distributed system, three phase faults on transmission lines are common. A three-phase is applied at bus 4 at $1 \mathrm{~s}$ with a fault resistance of $1 \Omega$. The fault is cleared after $0.2 \mathrm{~s}$. The wind speed is assumed constant at $10 \mathrm{~m} / \mathrm{s}$. The functioning of the composite control can be visualized by observing the flux linkages as shown in Fig. 5. Under the pre-fault condition, flux linkages are distortion free. The flux distortions are present during the transients and the controller brings the system to the steady state.

The proposed idea is compared to conventional PI control. The active power deviations and terminal voltage deviations are captured in Fig. 6. With PI control, the active power and terminal voltage oscillates and settles after $1.8 \mathrm{~s}$. Yet, with the proposed composite sliding mode control, the active power and terminal voltage oscillations are less and settles faster with less peak overshoot. The peak overshoot and settling time of DC link voltage with the proposed method are improved considerably when compared with the conventional PI control as shown in Fig. 7. One of the major drawback with FOSMC is the selection of optimum control gain value. The performance of the DFIG system with FOSMC with high control gain is depicted in Fig. 8 and the same is compared with the proposed method. Control chattering is another concern with FOSMC, but with the proposed approach, control chattering is minimized. This is because, when the sliding surface $\rho$ is approaching zero, control input tends to zero. The control input $u_{d}$ with FOSMC has undesirable oscillations and this can be visualized in Fig. 9.

\subsection{A three-phase fault at bus 5}

A three-phase fault is applied at bus 5 with fault resistance of $1 \Omega$. The flux linkage deviations are plotted in Fig. 10. As the fault is closer to the wind generation system, the distortions are enormous. After the fault, the active power and terminal voltage deviations are less with the proposed approach compared with the conventional approach. This can be visualized in Fig. 11. A similar result can be observed with the DC link voltage as shown in Fig. 12.

\subsection{Variable wind speed}

The power output of the wind energy system varies continuously with time because of the stochastic nature of wind. Hence, the DFIG system is simulated with variable wind speed profile and the corresponding active power is shown in Fig. 13. The zoomed plot of active power error is shown in Fig. 14 and it shows the efficacy of the proposed approach.

\section{Conclusions}

This paper presents a modified vector controlled DFIG system. The inner current loop with PI control in the conventional system is replaced with adaptive sliding mode control where the control gains are updated based on semi-definite barrier function. The proposed composite control is evaluated for a benchmark multi-machine power system model for various operating conditions. The proposed method has shown a considerable effect on the power system stability when compared to the conventional PI controller. The proposed method is robust to large disturbances like a three-phase fault.

\section{Acknowledgements}

Not applicable.

\section{Funding}

The authors declare that the research is not funded by any Government/ Private institution/agency.

Availability of data and materials

All the data is given in the paper or properly cited wherever necessary.

Authors' contributions

TSLVAR contributed to analysis, modelling, manuscript preparation, revision and typesetting of the manuscript. TSLVAR read and approved the final manuscript.

\section{Competing interests}

The authors declare that they have no competing interests.

Received: 22 August 2018 Accepted: 17 February 2019

Published online: 28 February 2019

\section{References}

1. Beltran, B., Benbouzid, M. E. H., \& Ahmed-Ali, T. (2012). Second-order sliding mode control of a doubly fed induction generator driven wind turbine. IEEE Transactions on Energy Conversion, 27(2), 261-269. https://doi.org/10.1109/ TEC.2011.2181515.

2. Evangelista, C. A., Pisano, A., Puleston, P., \& Usai, E. (2017). Receding horizon adaptive second-order sliding mode control for doubly-fed induction generator based wind turbine. IEEE Trans Control Syst Technol, 25(1), 73-84. https://doi.org/10.1109/TCST.2016.2540539.

3. Wu, F., Zhang, X.-P., Ping, J., \& Sterling, M. J. H. (2008). Decentralized nonlinear control of wind turbine with doubly fed induction generator. IEEE Trans Power Syst, 23(2), 613-621. https://doi.org/10.1109/TPWRS.2008.920073.

4. Hu, J., Nian, H., Hu, B., He, Y., \& Zhu, Z. Q. (2010). Direct active and reactive power regulation of DFIG using sliding-mode control approach. IEEE Transactions on Energy Conversion, 25(4), 1028-1039. https://doi.org/10.1109/ TEC.2010.2048754

5. Javadi, M., Malyscheff, A. M., Wu, D., Kang, C., \& Jiang, J. N. (2018). An algorithm for practical power curve estimation of wind turbines. CSEE Journal of Power and Energy Systems, 4(1), 93-102. https://doi.org/10.17775/ CSEEJPES.2016.00980.

6. Kenne, G., Nguimfack Ndongmo, J. D. D., Fochie Kuate, R., \& Fotsin, H. B. (2015). An online simplified nonlinear controller for transient stabilization enhancement of DFIG in multi-machine power systems. IEEE Trans Autom Control, 60(9), 2464-2469. https://doi.org/10.1109/TAC.2015.2427591.

7. Lei, Y., Mullane, A., Lightbody, G., \& Yacamini, R. (2006). Modeling of the wind turbine with a doubly fed induction generator for grid integration studies. IEEE Transactions on Energy Conversion, 21(1), 257-264. https://doi. org/10.1109/TEC.2005.847958. 
8. Lin, W., Wen, J., Cheng, S., \& Lee, W.-J. (2012). An investigation on the activepower variations of wind farms. IEEE Trans Ind Appl, 48(3), 1087-1094. https://doi.org/10.1109/TIA.2012.2190817.

9. Liu, X., Han, Y., \& Wang, C. (2017). Second-order sliding mode control for power optimisation of DFIG-based variable speed wind turbine. IET Renewable Power Generation, 11(2), 408-418. https://doi.org/10.1049/ietrpg.2015.0403.

10. Liu, Y., Wu, Q. H., Zhou, X. X., \& Jiang, L. (2014). Perturbation observer based multiloop control for the DFIG-WT in the multimachine power system. IEEE Trans Power Syst, 29(6), 2905-2915. https://doi.org/10.1109/ TPWRS.2014.2308900.

11. Mishra, Y., Mishra, S., Tripathy, M., Senroy, N., \& Dong, Z. Y. (2009). Improving stability of a DFIG-based wind power system with tuned damping controller. IEEE Transactions on Energy Conversion, 24(3), 650-660. https://doi. org/10.1109/TEC.2009.2016034.

12. Wang, N., Kang, C., Ren, D. (2015). Large-Scale Wind Power Grid Integration: Technological and Regulatory Issues. Elsevier.

13. Obeid, H., Fridman, L. M., Laghrouche, S., \& Harmouche, M. (2018). Barrier function-based adaptive sliding mode control. Automatica, 93, 540-544. https://doi.org/10.1016/j.automatica.2018.03.078.

14. Phan, V. T., \& Lee, H. H. (2012). Performance enhancement of stand-alone DFIG systems with control of rotor and load side converters using resonant controllers. IEEE Trans Ind Appl, 48(1), 199-210. https://doi.org/10.1109/TIA. 2011.2175883.

15. Shtessel, Y., Edwards, C., Fridman, L., \& Levant, A. (2014). Sliding mode control and observation. New York: Springer New York. https://doi.org/10.1007/9780-8176-4893-0

16. Tang, Y., Ju, P., Member, S., He, H., Qin, C., \& Wu, F. (2013). Optimized control of DFIG-based wind generation using sensitivity analysis and particle swarm optimization. IEEE Transaction Om Smart Grid, 4(1), 509-520 doi.org/10.1109/ TSG.2013.2237795.

17. Tummala, A. S. L. V., Alluri, H. K. R., \& Ramanarao, P. V. (2018). Optimal control of DFIG wind energy system in multi-machine power system using advanced differential evolution. IETE J Res, 1-12. https://doi.org/ 10.1080/03772063.2018.1466732.

18. World Wind Energy Market Update. (2017). Navigant research. Retrieved from https:// unw.navigantresearch.com/research/world-wind-energy-market-update-2017

19. Wu, F. (2009). Modelling and Control of Wind and Wave Energy Conversion. Ph.D. Thesis Submitted to the University of Birmingham, (January).

\section{Submit your manuscript to a SpringerOpen ${ }^{\circ}$ journal and benefit from:}

- Convenient online submission

- Rigorous peer review

- Open access: articles freely available online

- High visibility within the field

- Retaining the copyright to your article

Submit your next manuscript at $\boldsymbol{\nabla}$ springeropen.com 